\title{
Hearing loss in very preterm infants: should we wait or treat?
}

\author{
L'ipoacusia nei neonati estremamente prematuri: trattare subito o aspettare?

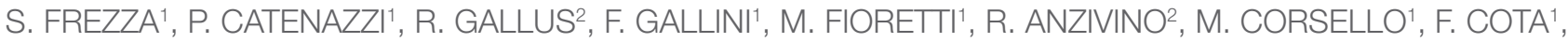 \\ G. VENTO', G. CONTI2 \\ ${ }^{1}$ Department of Woman and Child Health, Division of Neonatology, ${ }^{2}$ Department Head and Neck Surgery, Institute \\ of Otorhinolaryngology, Università Cattolica del Sacro Cuore, Fondazione Policlinico Universitario A. Gemelli IRCSS, \\ Rome, Italy
}

\section{SUMMARY}

This study investigated hearing threshold changes during the first year of corrected age (CA) in infants admitted in a neonatal intensive care unit (NICU). In 5 years, 239 infants with birth weight $(\mathrm{BW}) \leq 1,000 \mathrm{gm}$ and/or gestational age (GA) $\leq 30$ weeks were enrolled. Hearing was evaluated by oto-acoustic emission (OAEs) before discharge and auditory brainstem response (ABR) within 3 months of CA. Infants affected by unilateral or bilateral hearing loss were addressed to audiological follow-up until definitive diagnosis (within 6 months of CA). Changes in hearing threshold were also carefully analysed. 207 (86.6\%) infants had normal hearing while 32 infants (13.4\%) showed hearing loss (HL) at the confirmative ABR evaluation (9 mild, 16 moderate, 4 severe, 3 profound). The latter showed lower GA $(27.7 \pm 2$ vs $28.4 \pm 1.2 ; \mathrm{p}=0.0061)$ and BW $(950 \pm 390 \mathrm{vs}$ $1,119 \pm 326 \mathrm{gm} ; \mathrm{p}=0.0085)$. At final evaluation, 15 infants $(47 \%)$ recovered a normal hearing. HL was confirmed in 17 patients. Among these, 3 infants were addressed to audiological follow-up (one case of mild unilateral hearing loss (UHL) and two with moderate UHL), while in 14 cases (44\%) with bilateral sensory neural hearing loss (SNHL) (7 moderate, 4 severe, 3 profound) hearing aids were prescribed. They showed significantly lower GA and longer hospital stay in the NICU in comparison with infants without indication for audiological habilitation (18 infants) (GA $26.2 \pm 2.2$ weeks vs $28.4 \pm 2.4 ; p=0.01$; NICU stay $132 \pm 67$ vs $59 \pm 7 ; p=0.0002$ ). Definitive diagnosis was obtained at $5.9 \pm 1.3$ months of CA. Our study confirms the importance of audiological surveillance in preterm newborns. Hearing thresholds of preterm infants with hearing loss can change during the first year of CA and we observed normalisation in $47 \%$ of our patients. Most vulnerable to permanent SNHL were very preterm infants with a longer NICU stay, while a shorter stay represents a favourable prognostic factor for hearing improvement.

KEY WORDS: Preterm infants $\bullet$ NICU • Sensorineural hearing loss • Newborn Hearing Screening • Hearing Aids

\section{RIASSUNTO}

Un'ipoacusia permanente infantile (IPI) può avere gravi conseguenze sullo sviluppo del linguaggio e delle abilità cognitive. Le IPI congenite hanno una prevalenza di circa 1,5-3 nuovi casi per mille neonati. Esistono tuttavia alcuni gruppi di bambini, come quelli ricoverati in unità di terapia intensiva neonatale (UTIN), in cui il rischio può essere 10-20 volte maggiore. La diagnosi precoce delle IPI consente di adottare misure altamente efficaci di trattamento/abilitazione. Non vi è, tuttavia, uniformità nella gestione del follow-up di questi bambini, con difficoltà nella definizione fisiopatologica del deficit uditivo e nella sua quantificazione. Scopo dello studio è stato quello di valutare la prevalenza delle ipoacusie e i risultati del follow-up audiologico in una popolazione di prematuri dimessi dalla UTIN. Sono stati inclusi nello studio i neonati con EG $\leq 30$ settimane e PN $\leq 1.000 \mathrm{gr}$, nati nell'arco di 5 anni, dimessi dalla UTIN e seguiti presso il nostro Servizio di Follow-Up. Tutti sono stati sottoposti a registrazione di OAEs alla dimissione (dopo le 32 settimane di età post-mestruale) e ABR diagnostico (con strumenti e personale di laboratorio) entro i tre mesi di età corretta (EC). Tutti i bambini con ipoacusia mono- o bilaterale da lieve (soglia elettrofisiologia oltre 20, entro $40 \mathrm{dBnHL}$ ) a profonda (soglia > $90 \mathrm{dBnHL}$ ) sono stati controllati fino alla diagnosi audiologica definitiva, (entro $i$ 5-6 mesi di EC) e sono state verificate, in particolare, le eventuali modificazioni della soglia elettrofisiologica entro i 12 mesi di EC. Di 239 bambini valutati, 32 (13,4\%; EG $27 \pm 2$ sett, PN $950 \pm 390$ g) hanno presentato un'ipoacusia mono/bilaterale (9 lievi, 16 medie, 4 gravi, 3 profonde) ai tre mesi di EC. I 32 bambini con rilievo iniziale di ipoacusia hanno mostrato nei controlli successivi una normalizzazione della soglia uditiva in 15 casi (47\%) e in 3 casi un'ipoacusia monolaterale (1 caso lieve, 2 casi media) che non ha richiesto protesizzazione. In 14 casi (44\%) (EG $26,2 \pm 2,2$ sett, PN $820 \pm 330 \mathrm{~g}$ ) è stata confermata una diagnosi di ipoacusia neurosensoriale bilaterale (7 medie, 4 gravi, 3 profonde). In questi ultimi la diagnosi di conferma è stata completata entro il $5^{\circ}$ mese di EC, con protesizzazione acustica, attuata in media a 5,9 ( $\pm 1,3$ mesi) di EC. Lo studio conferma l'importanza dell'intervento audiologico nella gestione dei neonati estremamente prematuri. Le soglie uditive dei neonati pretermine con ipoacusia possono cambiare durante il primo anno di EC e noi abbiamo descritto una normalizzazione nel $47 \%$ dei nostri pazienti. Maggiormente predisposti all'IPI erano i neonati estremamente pretermine con una permanenza in UTIN più lunga, mentre una durata inferiore del ricovero si è rivelata essere un fattore prognostico favorevole per il miglioramento della soglia uditiva.

PAROLE CHIAVE: Neonati pretermine $\bullet$ UTIN •Ipoacusia neurosensoriale $\bullet$ Screening uditivo neonatale $\bullet$ Protesi acustiche 


\section{Introduction}

Permanent bilateral hearing loss (PHL) affects 1-3/1000 live births in wellborn infants and 2-4/100 infants in the neonatal intensive care unit (NICU) population ${ }^{1-3}$. In order to achieve effective treatment, congenital or perinatal hearing loss should be recognised within three months of life, with confirmative audiological diagnosis and early intervention before the 6 th month of age ${ }^{4}$. Early treatment is essential, as the first year of life is critical for normal development of speech and language, as well as intellectual and emotional growth ${ }^{5-7}$.

Preterm infants, with an increased risk for SNHL and auditory neuropathy spectrum disorders, are screened with auditory brainstem response (ABR) which allows objective and accurate assessment of the hearing function, with normal variation according to age due to physiological maturation of the auditory pathway ${ }^{7}$.

In the last few years, an improvement over time with regards to initial hearing thresholds in infants who failed newborn hearing screening has been reported in several studies ${ }^{1289}$. Changes in hearing threshold in infants can depend on factors temporary affecting the auditory periphery as well the neural pathway and/or on a delay in "auditory maturation" "-11. This latter factor seems to have a major role in premature infants, whose behaviour has been addressed in studies based on both heterogeneous ${ }^{12}$ or homogeneous ${ }^{12-14}$ groups of children.

Most of these studies lack uniformity with regards to the degree of prematurity, age of the first audiological diagnosis, definition of the hearing loss level and procedures and methodology of follow-up. In addition, they are usually based on retrospective/descriptive analysis of small series of infants.

This study reports the prevalence rates of SNHL in a cohort of preterm infants admitted in the NICU of "A. Gemelli" Hospital in Rome. We prospectively analysed changes in threshold during the first 12 months of CA in infants who resulted affected by hearing loss at initial evaluation on the basis of homogeneously applied objective procedures.

\section{Materials and methods}

From January 2009 to December 2014, 245 infants with birth weight $(\mathrm{BW}) \leq 1,000 \mathrm{gm}$ and/or GA $\leq 30$ weeks who were treated in our NICU were included in the study. These infants were enrolled prospectively in our followup monitoring, within the first weeks after discharge. Multidisciplinary health assessments occurred at 40 weeks of post menstrual age (PMA) and at 3, 6, 9 and 12 months of CA.
A schematic overview of the neonatal hearing screening program in our Division for NICU infants is shown in Figure 1. For the purpose of the present study, all infants underwent a diagnostic $\mathrm{ABR}$ recording at about 3 months (+ 2 weeks) of CA. Infants affected by hearing impairment where then addressed, within 5-6 months of CA, to confirmative audiological evaluation, which was aimed to eventually activate the rehabilitation programme. Hearing impaired children were further evaluated about every three months within the first year of CA.

The audiological evaluation consisted of history, otoscopy, oto-acoustic emission (OAEs), diagnostic ABR and tympanometry.

Infants affected by bilateral hearing loss were also evaluated with behavioural audiometry (behavioural observation audiometry or visual reinforcement audiometry, depending on the child's age and participation) after confirmative physiological diagnosis and fitting of hearing aids. Results of behavioural evaluation are not considered in the present study.

ABRs were recorded in a soundproof and electrically shielded room. All children were in natural sleep throughout the recording session. Both ears were sequentially tested. Stimuli were clicks $0.1 \mathrm{msec}$ duration and alternating polarity, presented by earphones (TDH-49P) at 21.1/sec. ABRs were recorded using the ICS Chartr EP system, with an ICS Chartr PA-800 preamplifier. Surface

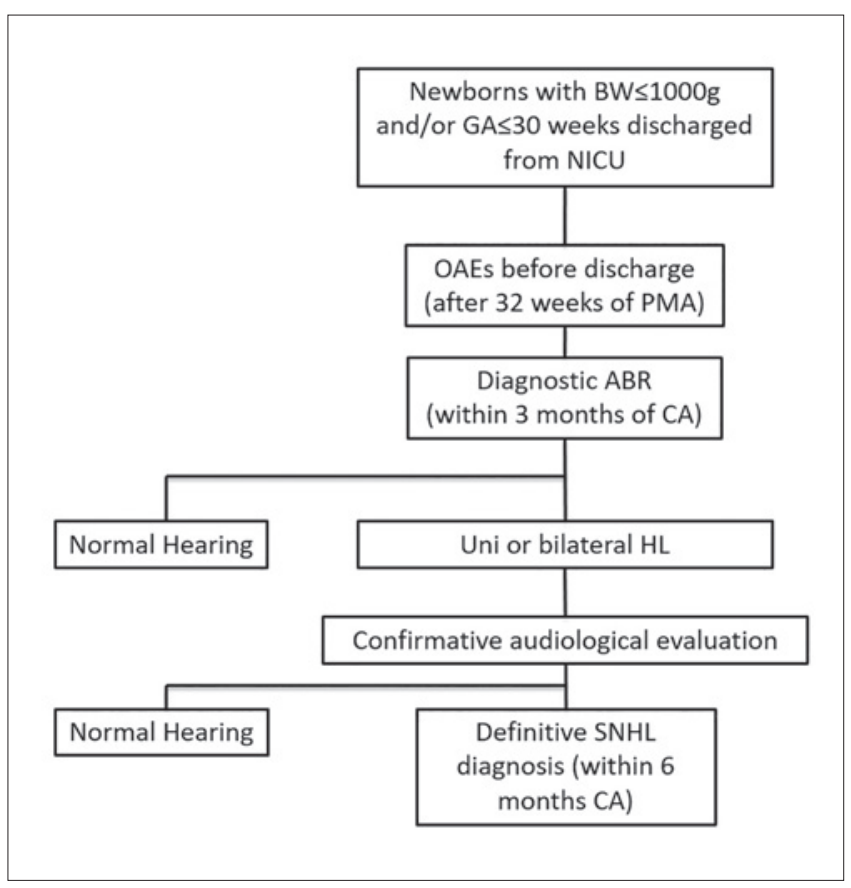

Fig. 1. Schematic overview of the neonatal hearing screening programme for preterm infants in "A. Gemelli" Hospital. 
electrodes where placed at the ipsilateral ear lobe (-), vertex (+), or just ventrally to the bregmatic fontanelle, and contralateral ear lobe (ground) and impedance was kept under $5 \mathrm{k} \Omega$. The signal was amplified $(100 \mathrm{k})$ and filtered $(50-3,000 \mathrm{~Hz})$. Each trace was obtained by averaging 500-1,500 single epochs and was replicated at least twice, mainly at the electrophysiological threshold level. This was determined as the lowest intensity level where a response could be assessed thorough the identification of the $\mathrm{V}$ wave, starting from $60 \mathrm{~dB} \mathrm{nHL}$, by a " $20 \mathrm{~dB}$ down - 10-5 dB up" procedure. ABR measurements were performed by an audiology technician under supervision of an expert physician. Our protocol did not include automatic ABR.

TEOAEs measurements were performed using the Madsen Accuscreen ${ }^{\circledR}$, which performs an evaluation of a patient's TEOAES through a noise-weighted averaging and counting of significant signal peaks. The stimulus sent through the probe is a non-linear click sequence at $60 \mathrm{~Hz}$ rate with a sound pressure level of 70-84 dB SPL with a self calibration depending on ear canal volume.

Tympanometry was performed with a Tympstar ${ }^{\circledR}$ by Granson Stadler with a 226/660 (depending on the age) $\mathrm{Hz}$ probe tone $(85 \mathrm{~dB}$ SPL $\pm 1.5 \mathrm{~dB})$.

Changes in hearing threshold were particularly analysed. Hearing loss was defined as: mild (20-40 dB nHL), moderate (41-70 dB nHL), severe (71-90 dB nHL), profound $(>90 \mathrm{~dB} \text { nHL })^{4}$.

Parents were supplied with detailed informing brochures about significance and importance of the path of audiological screening and rehabilitation, when needed.

With regard to terminology used to define the age of patients, the standardised definition of gestational age (GA), postmenstrual age (PMA) and corrected age (CA) was applied as reported by Engle in $2004{ }^{15}$.

For statistical analysis, continuous variables were presented as mean \pm standard deviation $(\mathrm{SD})$ and categorical variables as number and percentage. Comparisons between continuous variables were performed using Student's t-test. Comparisons between categorical variables were performed using the Fisher's exact test. A two-tailed $p<0.05$ was considered significant. Statistical analyses were performed with Graph Pad Prism 4 software.

\section{Results}

Among the 245 infants enrolled, only 6 (2.4\%) were lost to follow up.

At the initial ABR 207 of 239 (86.6\%) subjects showed normal hearing thresholds, while 32 (13.4\%) showed unilateral or bilateral HL ( 9 mild, 16 moderate, 4 se- vere, 3 profound HL). Infants with hearing impairment showed a significantly lower GA ( $27 \pm 2$ vs $28.4 \pm 1.2$ weeks; $p=0.0061)$ and BW (950 \pm 390 vs $1,119 \pm 326$ g; $\mathrm{p}=0.0085$ ) in comparison to normal hearing babies.

Substantial changes in hearing threshold were observed during follow-up. Fifteen of 32 children with an initial finding of bilateral HL (47\%) showed a normalisation of hearing threshold evaluations (Fig. 2). Figure 3 displays the changes in ABR in one of these infants. From an initial bilateral moderate/severe SNHL, there was a clear progressive improvement of hearing threshold. In particular, at the first ABR (performed at 40 weeks of PMA) the electrophysiological threshold was $60 / 50 \mathrm{~dB}$ nHL (right side) and $80 \mathrm{~dB}$ nHL (left side). When the baby was 3 months of CA, the threshold was unchanged on the right but showed a remarkable improvement on the left ( $30 \mathrm{~dB} \mathrm{nHL}$ ). In the following evaluation at 6 months of CA a substantial improvement of hearing was observed bilaterally, with threshold near to normalisation (left ear $30 \mathrm{~dB}$ nHL, right ear $20 \mathrm{~dB} \mathrm{nHL}$ ).

To better appreciate the effective improvement pattern of these 15 infants, their 30 ears were evaluated separately. Hearing threshold improved from a moderate loss to a normal level in 12 ears (40\%) and from a mild loss to normal hearing in 18 ears $(60 \%)$. The average threshold variation was $20 \pm 10.94 \mathrm{~dB} \mathrm{nHL}$ (range 10-45 dB nHL). Normalisation of hearing threshold was reached at the

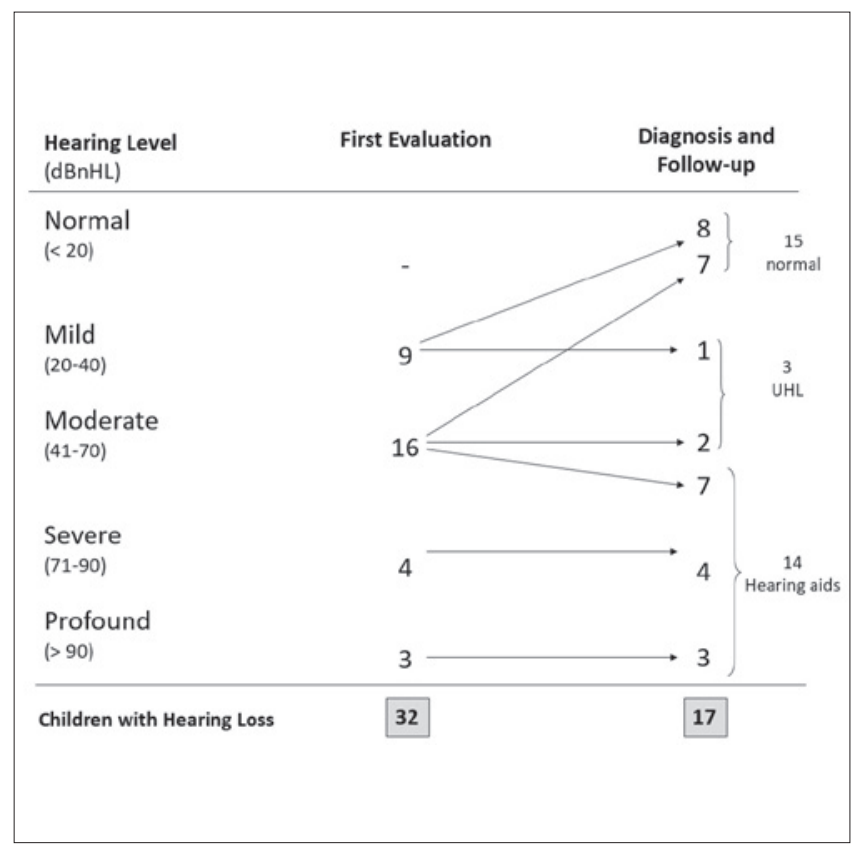

Fig. 2. Changes in hearing thresholds in our population at the time of first evaluation (ABR within 3 months of $C A$ ) and during hearing diagnosis and follow-up. 


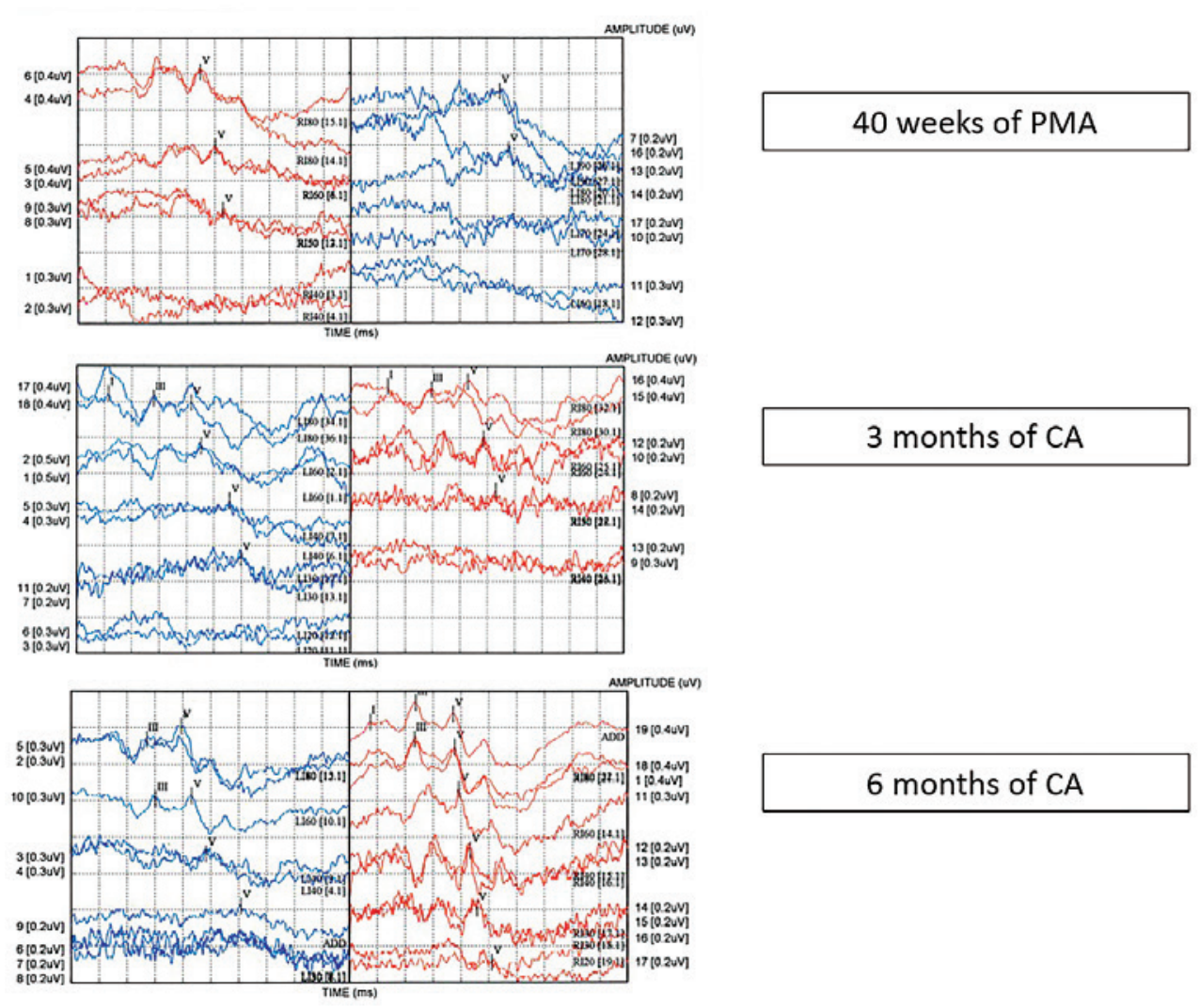

Fig. 3. Changes in hearing threshold in a preterm infant (GA 28.5 wk., PN $1160 \mathrm{~g}$ ) in ABR performed at 40 weeks of postmenstrual age (PMA), 3 months and 6 months of corrected age (CA). The red traces refer to the stimulation of the right ear, the blue traces refer to the left one.

mean age of $6.3(+1.3$; range 5-8) months of CA for mild loss and of $8.6(+3.4$; range 5-12) months of CA for moderate loss.

Among infants with initial diagnosis of hearing loss, the threshold remained unchanged in 17 cases (53.1\%): 10 cases of mild-moderate loss and all 7 cases $(21.9 \%)$ with higher degree of bilateral loss (4 severe, 3 profound).

Among 17 patients affected by confirmed hearing loss, 3 infants showed unilateral (mild to moderate) loss. In these cases, audiological and phoniatric monitoring was proposed and later improvement with recovery to normal hearing was observed within 15 months of CA. In the remaining 14 cases affected by bilateral SNHL ( 7 moderate, 4 severe, 3 profound), acoustic amplification by hearing aids was indicated.

A definitive diagnosis of SNHL was reached by the fifth month of CA. When indicated, hearing aids were fitted at the mean age of $5.9( \pm 1.3)$ months of CA.

None of our children were submitted to cochlear implantation (CI) during the time period of our study.

Table I shows the main neonatal features of infants with indication to aural habilitation (confirmed SNHL; 14 cases) and infants in whom amplification was not needed (normal and unilateral hearing loss; 18 cases). Infants addressed to amplification showed significantly lower GA and longer hospital stay in the NICU (GA $26.2 \pm 2.2$ weeks vs $28.4 \pm 2.4 ; \mathrm{p}=0.0122$ and NICU stay $132 \pm 67$ days vs $59 \pm 27 ; \mathrm{p}=0.0002)$.

\section{Discussion}

Our study consists of an analysis of a homogeneous population of very preterm infants, admitted to "A. Gemelli" Hospital NICU, and followed prospectively after discharge. In our study we applied homogenous timing to perform initial electrophysiological evaluation by diagnostic ABR in all infants. We believe that this evaluation at 2-3 months allows for better comparison among infants and neonatal features, and reduces the possibility to detect temporary auditory dysfunction and, as a consequence, the risk of initial overestimation of hearing loss and an unjustified and dangerous increase in parental anxiety.

The prevalence of hearing loss in our group of very preterm infants was $13.4 \%$ at initial evaluation and $5.9 \%$ at confirmative diagnosis. This latter value is in substantial agreement with the available literature data ${ }^{14} 16$. 
We observed a trend towards improvement of hearing threshold in the first months of life in many infants, as already observed in several previous studies. In particular, $47 \%$ of our babies showed normalisation of initial mild-moderate hearing losses at final diagnosis. Coenraad et al. ${ }^{1}$ showed an overestimation of hearing loss and an improvement in threshold (even with normalisation), in a heterogeneous population, also including term infants (GA median 34.7, interquartile range 27.3-39.3 weeks). Kang et al. ${ }^{2}$ reported an improvement in hearing threshold even if these authors evaluated only 13 preterm subjects for 6 months, without providing any neonatal features. Preterm infants were also studied by Jiang et al. ${ }^{17}$ who studied changes in hearing threshold in neonates born below 30 weeks of gestation at 28-42 of CA and found average changes from $28 \mathrm{~dB}$ at 28 weeks of $\mathrm{CA}$ to $13 \mathrm{~dB}$ at 42 weeks, without extending the audiological follow-up. Bovo et al. ${ }^{11}$ studied 7 premature children within an heterogeneous group of potential candidates to CI and found improvement from a severe/profound degree of hearing loss up to mild degree/normalisation in all cases.

Hof et al. ${ }^{9}$ retrospectively studied 14 preterm infants categorised as "refer" at hearing screening. These authors observed a tendency towards improvement of abnormal threshold in some subjects born at 28 weeks of GA or less. Among 3 children showing hearing improvement, two had moderate hearing loss with an initial diagnosis at one month of CA, while the third one had profound hearing loss initially diagnosed at only 33 weeks of PMA. Hof et al. ${ }^{9}$ suggested that lower GA at birth and lower birth weight may be associated with better prognosis for hearing improvement.

After separating our infants in two subgroups, with and without indication for amplification, we found that infants with indication for hearing aids showed significantly lower GA and longer stay in NICU in comparison with infants without indication to audiological treatment. Taking into account the results of audiological follow-up, our data suggests that higher GA and shorter NICU stay represent favourable prognostic factors for hearing improvement within the first year of life. On the contrary, lower GA at birth and longer stay in NICU should be considered unfa- vorable prognostic factors for degree of hearing loss and improvement of hearing after initial electrophysiological diagnosis. Our results, based on a larger group of infants and with a homogeneous benchmark for initial diagnosis, is in contrast with those of Hof et al. ${ }^{9}$.

Very premature infants are at high risk for hearing loss and their evaluation has to be prompt and accurate to ensure early (within the accepted boundary of 4-6 months of CA) activation of habilitation which can, in addition, promote auditory pathway maturation ${ }^{18-20}$. However, this category of children requires particular caution because of the commonly observed changes in auditory dysfunction. This aspect is critical in choice and timing of treatment, but also in communication and counseling to the parents of our patients. Accurate audiological surveillance is needed beyond the time of confirmative diagnosis. We found that most hearing threshold changes occur within about 6 months, but can be observed up to 12 months of CA. Our data suggest that changes in hearing threshold from initial diagnosis are more common in premature infants with higher GA at birth and shorter NICU stay and in mild/moderate degree of loss. On the contrary, our results suggest that changes are less likely to be found in infants with lower CA at birth and longer NICU stay and in cases with initial diagnosis of severe/profound hearing loss. However, we believe that reported observations of improvement (even to normalisation) of hearing in these categories of infants justify the recommendation of accurate audiological follow-up until 80-85 weeks of GA before changing habilitative indication, mostly in the case of CI ${ }^{9112122}$.

\section{Conclusions}

Our study confirms the key role of audiological intervention in the management of very premature infants due to the prevalence and characteristics of hearing dysfunction in these patients.

We recommend initial electrophysiological evaluation of these infants performed at 2-3 three months of CA and followed by confirmative diagnosis within 5-6 months of CA.

Table I. Clinical characteristics of infants without hearing aids (normal or unilateral hearing loss) or with indication for hearing aid (confirmed bilateral SNHL).

\begin{tabular}{lccc} 
& $\begin{array}{c}\text { Infants without hearing aids } \\
\text { (18 infants) }\end{array}$ & $\begin{array}{c}\text { Infants with hearing aids } \\
\text { (14 infants) }\end{array}$ & 0.0122 \\
Gestational age (weeks - mean \pm SD) & $28.4 \pm 2.4$ & $26.2 \pm 2.2$ & $\mathrm{nS}$ \\
Birth Weight (grams - mean \pm SD) & $1,045 \pm 333$ & $820 \pm 330$ & $\mathrm{nS}$ \\
SGA (\%) & 22.2 & 28.6 & 0.002 \\
NICU stay (days - mean \pm SD) & $59 \pm 27$ & $132 \pm 67$ & \\
\hline
\end{tabular}

NICU: Neonatal Intensive Care Unit; SGA: Small for Gestational Age; SNHL: Sensorineural Nearing Loss; SD: Standard Deviation. 
Accurate audiological follow-up in very premature infants should continue until 8-10 months of CA (in particular up to $80-85$ weeks in candidates to $\mathrm{CI}$ ).

Particular attention to possible changes in audiological diagnosis should be considered in infants with higher GA at birth, shorter admission in NICU and hearing loss of mild/ moderate degree.

Further studies are needed to better delineate conditions associated with uncertainty and variations in audiological data in premature infants and to increase reliability of the procedures of audiological diagnostic set-up.

\section{Conflict of interest statement}

None declared.

\section{References}

1 Coenraad S, Goedegebure A, Hoeve J. An initial overestimation of sensorineural hearing loss in NICU infants after failure on neonatal hearing screening. Int J Pediatr Otorhinolaryngol 2011;75:159-62. https://doi.org/10.1016/j.ijporl.2010.10.026.

2 Kang MY, Jeong SW, Kim LS. Changes in the hearing thresholds of infants who failed the newborn hearing screening test and in infants treated in the neonatal intensive care unit. Clin Exp Otorhinolaryngol 2012;5(Suppl 1):S32-6. https://doi.org/10.3342/ceo.2012.5.S1.S32.

3 Colella-Santos MF, Hein TA, de Souza GL, et al. Newborn hearing screening and early diagnostic in the NICU. Biomed Res Int 2014;2014:845308. https://doi.org/10.1155/2014/845308.

4 American Academy of Pediatrics, Joint Committee on Infant Hearing. Year 2007 position statement: principles and guidelines for early hearing detection and intervention programs. Pediatrics 2007;120:898-921. https://doi.org/10.1542/peds.2007-2333.

5 Yoshinaga-Itano C. Benefits of early intervention for children with hearing loss. Otolaryngol Clin North Am 1999;32:1089-102.

6 Moeller MP. Early intervention and language development in children who are deaf and hard of hearing. Pediatrics 2000;106:E43. https://doi.org/10.1542/peds.106.3.e43.

7 Guzzetta F, Conti G, Mercuri E. Auditory processing in infancy: do early abnormalities predict disorders of language and cognitive development? Dev Med Child Neurol 2011;53:1085-90. https://doi. org/10.1111/j.1469-8749.2011.04084.x.

8 Lim HW, Kim EA, Chung JW. Audiological follow-up results after newborn hearing screening program. Clin Exp Otorhinolaryngol 2012;5:57-61. https://doi.org/10.3342/ceo.2012.5.2.57.

9 Hof JR, Stokroos RJ, Wix E, et al. Auditory maturation in premature infants: a potential pitfall for early cochlear implantation. Laryngoscope 2013;123:2013-8. https://doi.org/10.1002/lary.24054.
10 Jiang ZD, Wang J, Brosi DM, et al. One-third of term babies after perinatal hypoxia-ischaemia have transient hearing impairment: dynamic change in hearing threshold during the neonatal period. Acta Paediatr 2004;93:82-7.

11 Bovo R, Trevisi P, Ghiselli S, et al. Is very early hearing assessment always reliable in selecting patiens for cochlear implants? A case series study. Int J Pediatr Otorinolaringol 2015;79:725-31. https:// doi.org/10.1016/j.ijporl.2015.02.033.

12 Martínez-Cruz CF, García Alonso-Themann P, Poblano A, et al. Hearing loss, auditory neuropathy, and neurological co-morbidity in children with birthweight $<750 \mathrm{~g}$. Arch Med Res 2012;43:45763. https://doi.org/10.1016/j.arcmed.2012.08.007.

13 Borkoski-Barreiro SA, Falcón-González JC, Limiñana-Cañal JM, et al. Evaluation of very low birth weight $(\leq 1,500 \mathrm{~g})$ as a risk indicator for sensorineural hearing loss. Acta Otorrinolaringol Esp 2013;64:403-8. https://doi.org/10.1016/j.otorri.2013.05.002.

14 van Dommelen P, Verkerk PH, van Straaten HL; Dutch Neonatal Intensive Care Unit Neonatal Hearing Screening Working Group. Hearing loss by week of gestation and birth weight in very preterm neonates. J Pediatr 2015;166:840-3. https://doi.org/10.1016/j. jpeds.2014.12.041.

15 Engle WA; American Academy of Pediatrics Committee on Fetus and Newborn. Age terminology during the perinatal period. Pediatrics 2004;114:1362-4.

16 Robertson CM, Howarth TM, Bork DL, et al. Permanent bilateral sensory and neural hearing loss of children after neonatal intensive care because of extreme prematurity: a thirty-year study. Pediatrics 2009;123:e797-807. https://doi.org/10.1542/peds.2008-2531.

17 Jiang ZD, Yin R, Wilkinson AR. Changes in hearing threshold between 28 and 42 weeks of age in babies born at under 30 weeks of gestation. Acta Paediatr 2015;104:e143-7. https://doi.org/10.1111/ apa.12920.

18 Kral A, O'Donoghue GM. Profound deafness in childhood. N Engl J Med 2010;363:1438-50. https://doi.org/10.1056/NEJMra0911225.

19 Sharma A, Dorman MF, Kral A. The influence of a sensitive period on central auditory development in children with unilateral and bilateral cochlear implants. Hear Res 2005;203:134-43. https://doi. org/10.1016/j.heares.2004.12.010.

20 Aimoni C, Crema L, Savini S, et al. Hearing threshold estimation by auditory steady state responses (ASSR) in children. Acta Otorhinolaryngol Ital 2018;38:361-8. https://doi.org/10.14639/0392$100 X-1463$.

21 Bovo R, Trevisi P, Zanoletti E, et al. New trends in rehabilitation of children with ENT disorders. Acta Otorhinolaryngol Ital 2017; 37:355-67. https://doi.org/10.14639/0392-100X-1426.

22 Palma S, Roversi MF, Bettini M, et al. Hearing loss in children with congenital cytomegalovirus infection: an 11-year retrospective study based on laboratory database of a tertiary paediatric hospital. Acta Otorhinolaryngol Ital 2019;39:40-5. https://doi. org/10.14639/0392-100X-2020.

Received: February 15, 2018 - Accepted: October 7, 2018

How to cite this article: Frezza S, Catenazzi P, Gallus R, et al. Hearing loss in very preterm infants: should we wait or treat? Acta Otorhinolaryngol Ital 2019;39:257-262. https://doi.org/10.14639/0392-100X-2116

Address for correspondence: Piero Catenazzi, Department of Woman and Child Health, Obstetrics and Neonatology Area, Università Cattolica del Sacro Cuore, Fondazione Policlinico Universitario A. Gemelli IRCCS, largo F. Vito 1, 00168 Rome, Italy. Tel. +39 0630154357. Fax +3906 63055301. E-mail: piero.catenazzi@policlinicogemelli.it 